\title{
Viewing the Past: Virtual Time Binoculars and the Edinburgh 1544 Reconstruction
}

\begin{abstract}
This paper discusses how a digital reconstruction of the Scottish capital of Edinburgh around the year 1544 was created and communicated to the public. It explores the development and reception of the Virtual Time Binoculars platform - a system for delivering virtual reality heritage apps suitable for use on most smartphones. The Virtual Time Binoculars system is placed in the context of earlier research into mobile heritage experiences, including Situated Simulations (G. Liestøl. 2009) and the Mirrorshades Project (C. Davies et al. 2014). The eventual virtual reality app is compared with other means of viewing the historic reconstruction, including online videos and an interactive museum and educational exhibit. It outlines the historical and technical challenges of modelling Edinburgh's sixteenth-century cityscape, and of distributing the eventual reconstruction in an immersive fashion that works safely and effectively on smartphones on the streets of the modern city. Finally, it considers the implications of this project for future developments in mobile exploration of historic scenes.
\end{abstract}

Keywords: Historical Reconstruction, Virtual Reality, Mobile Devices.

\section{Introduction}

Twenty-first-century cities are shaped by the priorities and planning decisions of previous generations. Yet many modern urban residents and tourists have only a vague awareness of the relationship between past and present cityscapes. One way to improve understanding of the evolution of our urban spaces is via reconstructions of historic scenes. Traditionally, reconstructions were either still pictures or hand-made models, typically printed in books or displayed as part of the interpretation at museums and heritage sites [1]. However, these methods of communicating with the public have major limitations. Most history books do not have vast sales, while conventional museum displays and information panels are inevitably fixed in specific locations (often some distance from the historic site they are representing).

Over the last twenty years digital technologies have revolutionised how reconstructions of historic sites are made and (potentially) experienced. Digital representations of past scenes involving interactivity, movement, and complex sound effects are now possible. Lately, major developments in virtual reality have improved the immersiveness of simulated environments. Yet the contexts in which these digital representations are viewed by the public have remained relatively traditional. Digital reconstructions tend to be shown as part of fixed museum installations, or are brief video clips included in documentaries or embedded in conventional websites. On occasions digitally created reconstruction images are even published as illustrations in conventional books [2]. In short, it is still assumed that people will primarily engage with reconstructions in indoor settings - either in the comfort of their own homes and workplaces, or in museums.

The mass adoption of smart phones has the potential to change this situation. People have become used to carrying complex digital devices in their handbags and pockets - providing new possibilities for portable digital interpretation of historic cityscapes. It is now technologically possible for users to view a digital reconstruction of a historic scene on a mobile device, at the same 
time as exploring those same spaces in reality today. The past and present appearance of a street can be experienced in tandem. However, currently, both heritage experts and digital developers have only begun to respond to these exciting opportunities.

This paper discusses how a recent reconstruction of the Scottish capital of Edinburgh in the 1540s was created and communicated to the public, and the efforts which were made to foster an immersive, yet portable, user experience. It will outline the historical and technological challenges of modelling a cityscape which can be accessed on mobile devices out of doors, and the development of the so-called Virtual Time Binoculars - a framework for delivering simple virtual reality apps suitable for most mainstream smart phones. Additional ways in which the reconstruction could be viewed (including online videos and an immersive museum exhibit) will also be discussed. Finally, it will consider the overall reception and use of the reconstruction, and possibilities for future development.

\section{Technical Background}

The Edinburgh 1544 reconstruction, and the associated Virtual Time Binoculars framework, were deliberately designed to be used out of doors and on the street (as well as in more controlled indoor settings). Accessing a digital reconstruction in an outside urban space raises certain challenges. Firstly, it is essential that on-street users can enjoyably engage with the virtual scene, while remaining safe in the actual twenty-first-century world which surrounds them. Secondly, there is the question of ensuring the virtual experience functions efficiently on ordinary smartphones, without asking too much of a mobile device's processing power, storage space, and battery consumption. In order to address these complications, the Virtual Time Binoculars framework drew on nearly a decade of research into how people interact with augmented reality, virtual reality, and smartphones.

As far back as 2009, Gunnar Liestøl and his colleagues at the University of Oslo developed the concept of Situated Simulations (or sitsim), using powerful location and orientation-aware smartphones and tablets to render a 3D virtual environment, which was then navigated through the user's position in the real world [3]. Users of sitsim were intended to view reconstructions via phone and tablet screens (rather than by headsets), and to travel around the virtual model by really walking about a heritage site. Liestøl's pioneering work demonstrated the outstanding possibilities of smartphones for presentating portable virtual reconstructions. However, the sitsim approach does have its limitations. There are practical problems associated with using real world movement to navigate a virtual environment in an uncontrolled space such as a city street. It frequently is not safe for a user to stand in the middle of a busy road holding up a smartphone in order to experience the perfect view of a historic scene. Additionally, the small screen of a mobile phone does not provide users with a particularly immersive experience, and can have significant problems with reflection when used out of doors in fine weather.

Between 2013 and 2015 researchers at the University of St Andrews worked on the Mirrorshades project [4]. This further examined the concept of seeing a real environment in tandem with a virtual representation of the same location. Yet, rather than showing reconstructions on a tablet or smartphone screen, the Mirrorshades project used a virtual reality (VR) headset equipped with stereo passthrough video cameras, and a magnetic indoor positioning system, providing a more immersive exploration of the reconstruction [5]. By using a VR headset that completely 
encompassed the user's view, the experience of the Mirrorshades parallel reality system was of shifting between two distinct and fully immersive environments, rather than only having a small 'window' onto the virtual environment as provided by a smartphone screen in the sitsim scenario.

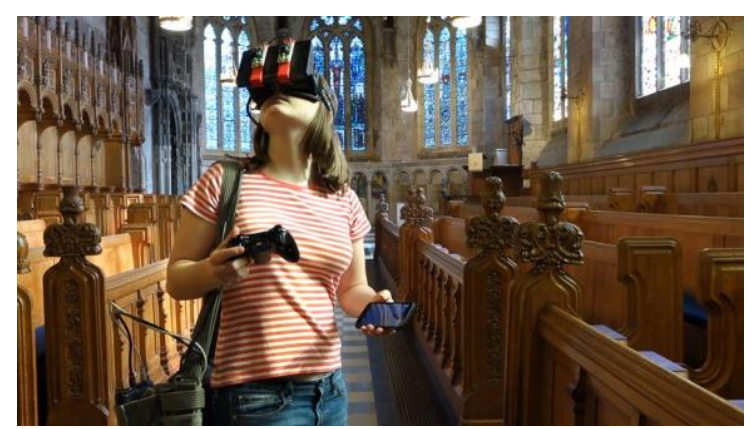

Fig. 1. The Mirrorshades parallel reality platform in use at the fifteenth-century St Salvator's Chapel. Still from youtube video [6].

Critically the Mirrorshades project logged experimental participants' walking behaviour, head movements, and viewing modes - which provided valuable information for the development of the Virtual Time Binoculars framework. Analysis of user studies within the Mirrorshades platform revealed that engagement with the virtual environment was predominantly performed while people were stationary. Users typically looked at their real world view while walking between perceived locations of interest, at which point they would stand still and look fully at the virtual environment. The users' behaviour can probably be explained by the fact that successful ambulation around a space is dependent on avoiding actual obstacles in the real world, causing viewers to focus on reality rather than any equivalent virtual environment. This acquires a particular importance when real and virtual environments do not share precisely the same layout, if the registration and position tracking between the two environments is imperfect, or if the real world situation is potentially hazardous (as is the case with a city street).

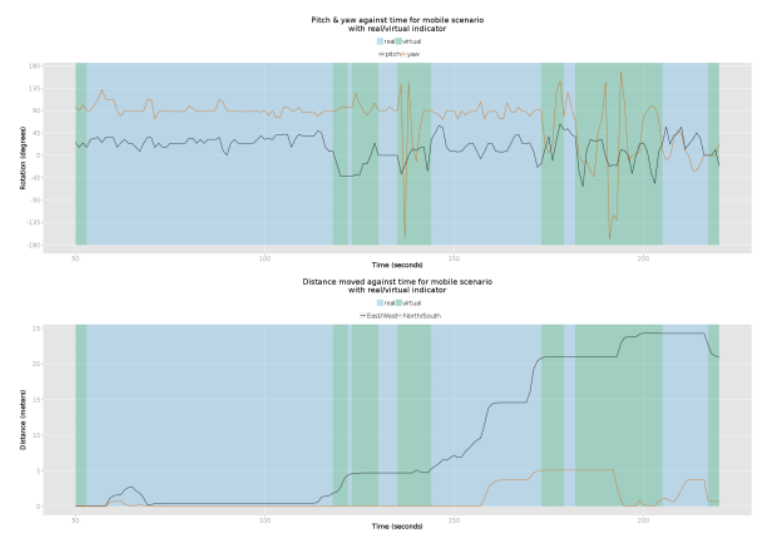

Fig. 2. Mirrorshades participants' walking behaviour and head movements contrasted against real and virtual visuals. 
The Mirrorshades behavioural observation raises questions about whether systems which allow users to explore real and virtual environments always need to provide a full 3D reconstruction. This is a important consideration as hosting a full $3 \mathrm{D}$ reconstruction places considerable demands on a smartphone in terms of processing power, download size, storage space, and battery life. The Mirrorshades project suggested that an experientially similar virtual reality platform might be achieved by using a combination of still 360 degree images, and videos captured from a 3D reconstruction. Rather than the user having to move to a new location to obtain a new view, movement becomes an intrinsic part of the media loaded into the virtual reality experience. Such a change promises significant benefits in outdoor virtual reality experiences. The smaller footprint of an app which uses a combination of still videos and short looping videos (instead of a full interactive 3D reconstruction) is a substantial boon for users, given the patchy nature of $3 \mathrm{G} / 4 \mathrm{G}$ data services in the United Kingdom, and the fact that many international visitors have prohibitively expensive or non-existent mobile data plans. Meanwhile, the fact that walking around the virtual reconstruction is no longer dependent on actual physical movement has substantial health and safety benefits in the context of a busy urban space.

This thinking heavily influenced decisions regarding the functionality of the Virtual Time Binoculars system. As a result of the Mirrorshades research it was determined that the Virtual Time Binoculars:

1. Did not need to provide users with a completely free-roaming exploration of a 3D reconstruction. Instead a more focused 'guided tour' approach would fit with most users' tendency to concentrate on locations of perceived interest.

2. Movement between locations in the reconstruction should not be dictated by the users' actual movements in the real world (a feature that raises considerable safety issues in a busy urban space).

3. Users should be able to switch easily between a screen view and a headset view, allowing them to combine a highly immersive virtual reality experience, with a more 'window-like' screen based experience (which might be preferable in some urban spaces).

\section{$3 \quad$ Identifying 1540s Edinburgh as a Place to Reconstruct}

The Virtual Time Binoculars framework was initially launched for use with a 3D model of Edinburgh in the 1540s. Sixteenth-century Edinburgh was selected as a suitable site to reconstruct for a variety of reasons. First and foremost, as the capital of Scotland and a world heritage site, Edinburgh is a site of international importance [7]. Yet heritage interpretation for its sixteenth-century history is patchy at best. Indeed, before the Edinburgh 1544 project, there were no publicly available digital reconstructions of the sixteenth-century cityscape. This gap is surprising as before 1603 Edinburgh was the capital of an independent kingdom, and dominated Scottish trade and politics.

The year 1544 was specifically focused on, as both a tumultuous time in the city's history, and because of the existence of an early bird's-eye view plan from this time. In May 1544 the Scottish capital was attacked by an English army with instructions to 'burn Edinburgh town' leaving it 'so razed and defaced...that there may remain forever a perpetual memory of the vengeance of God' [8]. In fact, the eventual outcome was slightly less cataclysmic. The English failed to take 
Edinburgh Castle, and departed after burning sections of the capital, and sacking the Abbey and Palace of Holyrood [9].

Among the English forces in May 1544 there was a military engineer named Richard Lee, who created a remarkable aerial view of how Edinburgh appeared during the English attack. The bird'seye plan was probably intended to inform Henry VIII and his advisors about how the English operations unfolded [10]. Lee's drawing is now in the British Library, and is the oldest (relatively) realistic representation of the Scottish capital [11]. The Lee plan formed the inspiration for the Edinburgh 1544 reconstruction. Evidence from Lee's drawing was supplemented with information from archaeological reports, sixteenth-century written descriptions of Edinburgh, and other early visual depictions - notably James Gordon of Rothiemay's seventeenth-century engravings of the capital and William Edgar's mid-eighteenth-century maps [12].

\section{$4 \quad$ Creating the Reconstruction}

Like most cities, Edinburgh was smaller in the sixteenth century than today, being focused on the quarter now known as the Old Town. In 1544 the built-up area spanned about $2 \mathrm{~km}$ from east to west, and about $0.5 \mathrm{~km}$ from north to south at its widest points. Although diminutive in terms of twenty-first-century cities, this is a relatively large area to reconstruct digitally. Creating a reconstruction of the whole of sixteenth-century Edinburgh (including the associated suburb of the Canongate) was an ambitious undertaking, which posed challenges regarding historical research, modelling time, and ensuring that the eventual digital output was not unduly large for use on mobile devices.

The underlying terrain for the reconstruction was created with World Machine and was informed by modern OS map data [13]. Some adjustments were made to take into account changes in Edinburgh's geography - notably the disappearance of the large stretch of water known as the Nor Loch (formerly located where Waverley Station now stands). The landscape was then imported into the gaming engine Unreal Engine 4, and modern and historic maps were overlaid on the 3D terrain, providing a guide for the layout of the historic street plan [14].

Unfortunately none of the sixteenth or seventeenth images of Edinburgh were sufficiently geographically accurate to be used as the base for the reconstruction's street plan without major distortion. The oldest plan which successfully layered onto the 3D terrain was William Edgar's map from about 1765 [15]. The Edgar plan pre-dates the main eighteenth-century redevelopment of Edinburgh. However, some boundaries did shift between the sixteenth and mid-eighteenth centuries. In particular the frontages of buildings had a tendency to encroach onto the streets. Using the eighteenth-century street plan as a base layer therefore almost certainly introduced elements of inaccuracy into the reconstruction.

The sixteenth-century buildings were initially modelled in SketchUp and then imported into Unreal [16]. Major sites (such as Holyrood Palace, St Giles' Kirk, the Netherbow, and Trinity College) were based on detailed historical research. However, a combination of time constraints and gaps in the historical sources meant that many of the ordinary urban residences were generic buildings, located approximately according to historic property boundaries [17]. The reconstruction process highlighted the numerous lacunae in our understanding of Edinburgh's early sixteenth century domestic architecture (in particular the design of vernacular timber structures) - and it is 
to be hoped that the Edinburgh 1544 project will trigger further discussion and research on this topic.

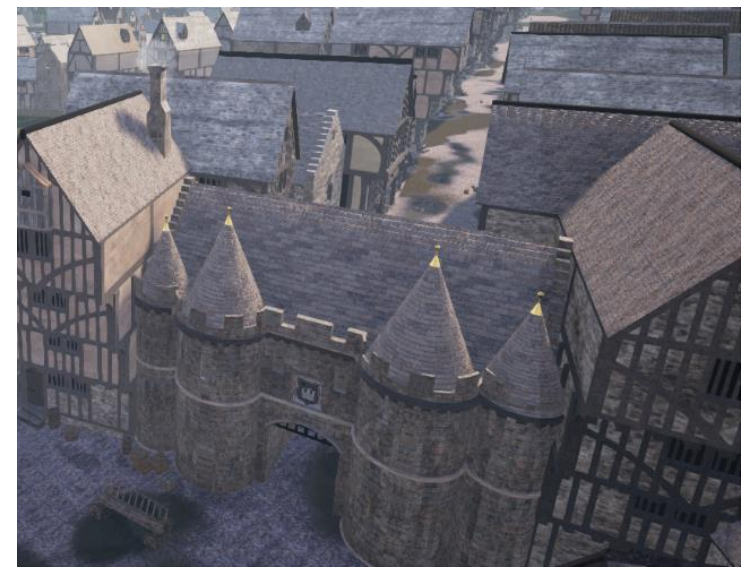

Fig. 3. Reconstruction of the Netherbow from the Edinburgh 1544 project. This was one of the most important gateways to Edinburgh in the sixteenth century (and the focus of significant fighting in 1544). However, the structure was completely demolished in the eighteenth century as it was obstructing traffic.

\section{Communicating the Reconstruction}

A major advantage of digital reconstructions (as against traditional drawings or physical models) is the variety of media that can be generated from one model. A range of digital outputs were created from the Edinburgh 1544 model in Unreal Engine 4. The core output was of course the content included in the Edinburgh 1544 Virtual Time Binoculars app. However, additional videos and spherical media were generated for embedding in web-resources and sharing on social media. A full 3D reconstruction which allows users to roam freely about the virtual historic city was also developed for use in museum exhibits and educational contexts.

\subsection{The Virtual Time Binoculars}

The Edinburgh 1544 Virtual Time Binoculars app provides a tour through the 3D reconstruction of Scotland's early sixteenth-century capital [18]. Following a brief introductory video there is an interactive historic map, with a marker indicating the user's current location, and buttons to select a range of key sites. Some of these historic sites exist today in a modified form (like St Giles' Kirk), while others have been completely demolished (such as the Netherbow). Selecting a site starts a video of a relevant section of the $3 \mathrm{D}$ reconstruction (for instance the journey along a particular street), providing users with a sense of movement and discovery in their experience of the model. Upon the completion of the video users reach a 360 degree virtual historic scene, which can be explored either via a mobile device's touch-screen, or through a simple virtual reality headset of the Google Cardboard or Google Daydream type [19]. Users can switch between touchscreen and headset mode through an icon in the corner of the screen. Interactive information points 
are located within the 360 view, which can be selected to access brief factual information about a site's history and to view early images of the location (such as paintings or engravings), giving users a hint of the actual historical sources which informed the reconstruction process. This presentation of the 3D reconstruction was devised with the intention of creating a package which is not unduly large for use on standard smartphones, can be used in outdoor and indoor environments, but which nevertheless provides a degree of immersiveness, and does not significantly restrict how a large proportion of people tend to interact with virtual reality experiences.

Virtual Time Binoculars apps are designed for use on Android and Apple devices in conjunction with Google Cardboard type viewers, or as an extended android app for use with Google Daydream. The Virtual Time Binoculars platform consists of three parts: the package creation system, the package management system, and the app framework. The system is designed to enable the easy creation of virtual reality tour apps. The tours can contain a variety of types of media files including 360 photospheres, videospheres, videos, still images, and audio. All the visual media can be displayed stereoscopically. Tours can be set up to be linear or involve navigation via a map system. The packages consist of an XML file describing the tour and the relevant media files in a zip file.

Currently, package creation is undertaken using an Omeka plug-in. Omeka is a content management system for online digital collections [20]. It provides Dublin core metadata and is easily extendable. The plug-in creates a private online exhibit of the contents of the app. This allows the alignment of the hotspots to be checked. All of the elements of the tours are items in Omeka and nodes in the exhibit. The package system creates an XML file with URLs referring to the media files. When the package is exported to the package management system the XML file is sent to the package management system which copies files to a local location, adds them to a zip file, and makes the media references local to the zip.

The package management system controls the relationship between packages and their content and apps. It stores the packages and is used to create lists of packages for apps. These lists contain metadata about the packages including a thumbnail and when they were last updated.

The app framework is a system which takes a list of packages, downloads them, and renders the packages. There are three implementations of the app framework, namely for Android (Google Cardboard), Extended Android (Google Daydream), and Apple (Google Cardboard). The three frameworks are configured with a number of parameters including the package list URL, and whether there are to be multiple packages or just one. Single package apps start by downloading the single package and unpacking it. The package list tells the app whether it is to be downloaded automatically, or it will require the user to request download.

The apps allow two modes of interaction, virtual reality mode or wide screen mode. In VR mode any flat media is rendered onto a plane in front of the user, while spherical media is rendered on the inside of a sphere. In Cardboard VR versions users focus their gaze on a hotspot in order to select it. The Daydream app uses the hand-held controller to select points. When the Cardboard app is in wide screen mode the flat media is rendered on an overlay layer, though spherical media is still rendered on the inside of a sphere. In wide screen mode hotspots are selected by touching them.

The apps use OpenGL to render the media which allows them to also include 3D artefacts. To use the virtual reality mode a mobile device must have a gyroscope sensor to track its orientation. This means that on Apple devices the virtual reality mode only works on iPhone 4 or subsequent 
models. All Daydream compatible phones have gyroscope sensors, but not all older Android phones have this feature.

\subsection{Website, Social Media, and Interactive Exhibit}

In addition to the Virtual Time Binoculars app, an Edinburgh 1544 website was created. This serves the dual purpose of publicising the app, and provider greater context on the reconstruction [21]. Videos from the reconstruction were also posted on the Vimeo video sharing site, and photospheres were uploaded to Roundme [22]. It was felt that it was important to provide a range of ways in which people could access the reconstruction, not of all which should involve having to install an app on a mobile device (a relevant consideration as 49 percent of people aged over 55 still do not have a smartphone) [23]. Having video content on Vimeo also facilitated sharing on social media and via traditional media outlets.

An interactive exhibit, which allows users to explore freely the full 3D reconstruction of Edinburgh in 1544, was also developed for use in museums and educational contexts. This was exhibited at public events at the Museum of Edinburgh, and at Riddle's Court (where it was one of the attractions for the Edinburgh Doors Open Day). It has also been used in educational contexts including local schools and the Curiosity Live science festival in Glasgow. This exhibit can be used either with a traditional flat screen, or an Oculus Rift virtual reality headset [24]. It has not, as yet, been generally released to the public, partly because the current version requires considerable processing power and a high-quality graphics card in order to function quickly. All of the fully released content, both the Edinburgh 1544 Virtual Time Binoculars app and the online videos and photospheres, are available free of charge.

\section{Reception and Use of the Reconstruction}

The online videos on Vimeo have proved to be by far the most heavily used of the Edinburgh 1544 project outputs. The most popular of these videos has over 61,000 views, while another has in excess of 33,000 views [25]. To put these figures in context, it has been claimed that an average academic monograph on a historical topic sells in the region of 200 copies [26]. Clearly, making content freely available online can enable historical research to reach much wider audiences than traditional academic publishing.

When compared with the number of video views, the Edinburgh 1544 Virtual Time Binoculars apps have had significantly fewer downloads. The relative popularity of the videos is probably attributable to a range of reasons, including the fact the videos were linked to by major media organisations. It also perhaps reflects people's familiarity with watching online video content, the ease with which videos can be shared, and the slightly lesser time and commitment involved in clicking on an online video as against downloading and starting to use an app. That being said, the app has fulfilled its aim of enabling people to take a reconstruction out onto the street. It has been used by tour guides, and has generally received positive feedback. The app also generated considerable media interest around the time of its launch, leading to reporting in print editions of The Times, the Daily Express, the $i$, The Scotsman, and The Herald [27]. The BBC also subsequently approached the app creation team to discuss Edinburgh's experiences in 1544 for a Newsnight 
report - arguably indicating that the app succeeded in its overall aim of raising the profile of an under-appreciated moment in Edinburgh's history [28].

\section{Considerations for Future Development}

At the heart of the Edinburgh 1544 project lay the creation of a full 3D digital reconstruction of a sixteenth-century cityscape. The project clearly demonstrated that modern modelling software and gaming engines can readily handle reconstructions on the scale of an entire urban community. From the perspective of historical reconstruction the key limitations in creating city-wide representations now lie in the amount of preliminary historical research required and the man-hours it takes to model the virtual cityscape - which are still significant considerations.

The Edinburgh 1544 project further demonstrated the viability of creating an app which provided an immersive experience of a pre-modern cityscape, while being of a size to work effectively on ordinary smartphones. The Virtual Time Binoculars framework is now being tested on other reconstructions, with satisfactory initial results. The project arguably also highlighted the importance of accompanying new apps with videos and other content placed on social media and other media sharing platforms which people are already familiar with. Apps have tremendous potential for onstreet heritage interpretation experiences, but they should not be the sole focus of future development. Moving forward, the project team would like to introduce into the Virtual Time Binoculars apps (and potentially other resources) more information on the historical sources behind the reconstructions. In so doing they aim to achieve a state where the evidence from the past, the visualization of the past, and experience of the present seemlessly integrate - encouraging users to embark on their own research journeys into the spaces and buildings of earlier generations.

\section{References}

1. For an overview of traditional reconstruction processes see Davison, B.: Picturing the Past Through the Eyes of Reconstruction Artists. English Heritage, Stroud (1997).

2. For example, Gorski, J., Packer, J.: The Roman Forum: A Reconstruction and Architectural Guide. Cambridge University Press, New York (2015).

3. Liestøl, G.: Augmented Reality and Digital Genre Design - Situated Simulations on the iPhone. In: Proceedings of ISMAR 2009 IEEE International Symposium on Mixed and Augmented Reality - Arts, Media and Humanities, pp. 29-34. IEEE, Orlando (2009). Also see Situated Simulations Homepage, http://sitsim.no/, last accessed 2019/2/27.

4. Davies, C., Miller, A., and Allison, C.: A View from the Hill: Where Cross Reality Meets Virtual Worlds In: Proceedings of the 20th ACM Symposium on Virtual Reality Software and Technology, p. 213 ACM, Edinburgh (2014).

5. Davies, C., $\mathrm{PhD}$ thesis at the University of St Andrews, http://hdl.handle.net/10023/8098, last accessed 2019/2/26.

6. Youtube Video, https://www.youtube.com/watch?v=UsDRPjDwr8A, last accessed 2019/2/26.

7. UNESCO World Heritage List, Entry for the Old and New Towns of Edinburgh, https://whc.unesco.org/en/list/728, last accessed 2019/2/26.

8. Bain, J.: The Hamilton Papers: Letters and Papers Illustrating the Political Relations of England and Scotland in the XVIth Century, vol. 2, p. 326. General Register House, Edinburgh (1892). 
9. Bain, J.: The Hamilton Papers: Letters and Papers Illustrating the Political Relations of England and Scotland in the XVIth Century, vol. 2, p. 369. General Register House, Edinburgh (1892).

10. Bain, J.: The Hamilton Papers: Letters and Papers Illustrating the Political Relations of England and Scotland in the XVIth Century, vol. 2, p. 384. General Register House, Edinburgh (1892).

11. British Library Online Gallery, http://www.bl.uk/onlinegallery/onlineex/unvbrit/a/001cotaugi00002u00056000.html, last accessed 2019/1/5.

12. National Library of Scotland Digital Image of James Gordon of Rothiemay's Edinodunensis Tabulam, http://maps.nls.uk/view/74475427, last accessed 2019/1/5. National Library of Scotland Digital Image of William Edgar's Plan of the City and Castle of Edinburgh, http://maps.nls.uk/view/74400010, last accessed 2019/1/5.

13. World Machine Homepage, https://www.world-machine.com, last accessed 2019/2/2.

14. Unreal Engine 4 Homepage, https://www.unrealengine.com/en-US/what-is-unreal-engine-4, last accessed 2019/1/5.

15. National Library of Scotland Digital Image of William Edgar's Plan of the City and Castle of Edinburgh, http://maps.nls.uk/view/74400010, last accessed 2019/1/5.

16. SketchUp Homepage, https://www.sketchup.com, last accessed 2019/1/5.

17. For discussion of Edinburgh's early modern property boundaries see Tait, R.: Configuration and Dimensions of Burgage Plots in the Burgh of Edinburgh. Proceedings of the Society of Antiquaries of Scotland 136, 297-310 (2006).

18. Edinburgh 1544 Virtual Time Binoculars App webpage, https://www.smarthistory.co.uk/Edinburgh1544/download.html, last accessed 2019/2/24.

19. Homepage for Google Cardboard, https://vr.google.com/cardboard/, last accessed 2019/2/24. Homepage for Google Daydream, https://vr.google.com/daydream/, last accessed 2019/2/24.

20. Homepage for Omeka, https://omeka.org/, last accessed 2019/2/24.

21. Homepage for Edinburgh 1544, https://www.smarthistory.co.uk/Edinburgh1544/, last accessed 2019/2/27.

22. Vimeo introductory video for Edinburgh 1544, https://vimeo.com/208677167, last accessed 2019/2/27. Photosphere of St Giles' Kirk, https://roundme.com/tour/171650/view/439692/, last accessed 2019/2/27.

23. Ofcom Communications Market Report for 2018, https://www.ofcom.org.uk/_data/assets/pdf_file/0022/117256/CMR-2018-narrative-report.pdf, last accessed 2019/2/27.

24. Homepage for Oculus Rift, https://www.oculus.com/rift/, last accessed 2019/2/27.

25. Edinburgh 1544 Introductory video, https://vimeo.com/224189702, and Edinburgh 1544 Townscape Video, https://vimeo.com/208677167, both last accessed 2019/2/27.

26. Dalton, M.: The Publishing Experiences of Historians. Journal of Scholarly Publishing 39 (3), 197-240 (2008).

27. Mair, G.: Edinburgh re-emerges from past. The Times. 18 March 2017. Milmo, C.: The really Old Town: $16^{\text {th }}$-century Edinburgh is brought back to life. i. 18 March 2017. Christison, G.: New virtual view of very Auld Reekie. Daily Express.18 March 2017. O’Leary, D.: Step back in time as app visits capital in 1544. The Herald. 18 March 2017. Pringle, F.: Old, lost Edinburgh digitally recreated. The Scotsman. 18 March 2017.

28. BBC Newsnight report on the Rough Wooing, https://www.youtube.com/watch?reload=9\&v=nqbdSVZ5ZME\&list=PLJxnQXiytA_Qc0B57aViue2G3DPet1Z0L\&index $=1, \quad$ originally broadcast on 6 April 2017. 